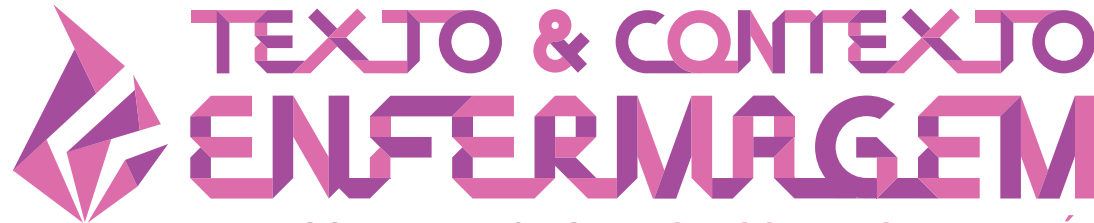

TEXT \& CONTEXT NURSING TEXTO \& CONTEXTO ENFERMERÍA

\section{NURSING PRACTICES IN PERIPHERAL VENOUS CATHETER: PHLEBITIS AND PATIENT SAFETY}

\author{
Anabela de Sousa Salgueiro-Oliveira ${ }^{1}$ \\ Marta Lima Basto ${ }^{2}$ \\ Luciene Muniz Braga ${ }^{3}$ (D) \\ Cristina Arreguy-Sena 4 \\ Michele Nakahara Melo ${ }^{5}$ \\ Pedro Miguel dos Santos Dinis Parreira' \\ 'Escola Superior de Enfermagem de Coimbra. Coimbra, Portugal. \\ 2Escola Superior de Enfermagem de Lisboa. Lisboa, Portugal. \\ ${ }^{3}$ Universidade Federal de Viçosa. Viçosa, Minas Gerais, Brasil. \\ ${ }^{4}$ Universidade Federal de Juiz de Fora, Faculdade de Enfermagem. Juiz de Fora, Minas Gerais, Brasil. \\ 5Universidade de São Paulo, Programa de Pós-Graduação em Enfermagem na Saúde do Adulto, Escola de Enfermagem. \\ São Paulo, São Paulo, Brasil.
}

\begin{abstract}
Objective: to understand the nursing practices related to peripheral venous catheter and to identify deviations related to the scientific evidence regarding the prevention of phlebitis.

Method: qualitative study with data collection by means of participant observation techniques and semistructured interviews, with 26 and 15 nurses, respectively, from a Portuguese hospital. Data content analysis was performed.

Results: In the category "nursing actions", nursing practices related to: selection of catheter insertion site and its caliber size, evaluation of insertion site for signs of inflammation, insertion site dressing, disinfection of accessories, hand hygiene and patient participation in care emerged. There were situations of deviations in these practices in relation to scientific evidence.

Conclusion: Nursing practices presented deviations in relation to scientific evidence, and were influenced by the size of the institution, patient characteristics, and lack of knowledge of nurses regarding certain actions that pose a risk to patient safety. The creation of protocols and the implementation of continuous education are fundamental for the acquisition of competencies by nurses, for correcting deviations and providing a safe quality nursing care to the patient.
\end{abstract}

DESCRIPTORS: Peripheral cannulation. Vascular access devices. Nursing care. Nursing. Phlebitis. Patient safety. 


\section{PRÁTICAS DE ENFERMAGEM NO CATETERISMO VENOSO PERIFÉRICO: A FLEBITE E A SEGURANÇA DO DOENTE}

\section{RESUMO}

Objetivo: conhecer as práticas de enfermagem relacionadas com o cateterismo venoso periférico e identificar desvios relativos às evidências científicas no que diz respeito à prevenção de flebite.

Método: estudo qualitativo com coleta de dados através das técnicas de observação participante e entrevista semiestruturada, com 26 e 15 enfermeiros, respectivamente, de um hospital Português. Foi realizada análise de conteúdo dos dados.

Resultados: na categoria Ações de enfermagem, emergiram práticas de enfermagem relacionadas com: seleção do local de inserção do cateter e seu calibre, avaliação do local de inserção quanto aos sinais inflamatórios, curativo na inserção, desinfecção de acessórios, higienização das mãos e participação do doente nos cuidados. Verificaram-se situações de desvios nessas práticas em relação às evidências científicas.

Conclusão: as práticas de enfermagem apresentavam desvios em relação às evidências científicas, sendo influenciadas por dimensões institucionais, características dos doentes, e desconhecimento dos enfermeiros acerca de determinadas ações que colocam em risco a segurança do doente. A elaboração de protocolos e a implementação da Educação Continuada são fundamentais para a aquisição de competências pelos enfermeiros, para correção dos desvios e prestação de uma assistência de enfermagem segura e com qualidade para o doente.

DESCRITORES: Cateterismo periférico. Dispositivos de acesso vascular. Cuidados de enfermagem. Enfermagem. Flebite. Segurança do paciente.

\section{PRÁTICAS DE ENFERMERÍA EN EL CATETERISMO VENOSO PERIFÉRICO: LA FLEBITE Y LA SEGURIDAD DEL PACIENTE}

\section{RESUMEN}

Objetivo: conocer las prácticas de enfermería relacionadas con el cateterismo venoso periférico e identificar desvíos relativos a las evidencias científicas en lo que se refiere a la prevención de flebitis.

Método: estudio cualitativo con la recolección de datos a través de técnicas de observación participante y entrevistas semiestructuradas con 26 enfermeros y 15, respectivamente, de un hospital portugués. Se realizó un análisis de contenido de los datos.

Resultados: en la categoría Acciones de enfermería, surgieron prácticas de enfermería relacionadas con: selección del lugar de inserción del catéter y su calibre, evaluación del lugar de inserción en cuanto a los signos inflamatorios, curativo en la inserción, desinfección de accesorios, higienización de las manos y participación del paciente en el cuidado. Se verificaron situaciones de desvíos en esas prácticas en relación a las evidencias científicas.

Conclusión: las prácticas de enfermería presentaban desvíos a las evidencias científicas, siendo influenciadas por dimensiones institucionales, características de los enfermos, y desconocimiento de los enfermeros acerca de determinadas acciones que ponen en riesgo la seguridad del paciente. La elaboración de protocolos y la implementación de la Educación Continua son fundamentales para la adquisición de competencias por los enfermeros, para la corrección de las desviaciones y la prestación de una asistencia de enfermería segura y con calidade para el paciente.

DESCRIPTORES: Cateterismo periférico. Dispositivos de acceso vascular. Cuidados de enfermería. Enfermería. Flebitis. Seguridad del paciente. 


\section{INTRODUCTION}

The peripheral venous catheter (PVC) is an essential material resource in the hospital context, used for the administration of fluids, nutrients, drugs and blood products, as well as in the collection of blood for examinations. ${ }^{1-3}$ Its use can cause complications, which can impact the patient's safety and well-being, phlebitis being one of the most frequent complications, with incidence rates ranging from $4.5 \%$ to $60 \%{ }^{2,4-7}$ In view of the high incidence of phlebitis and the safety and well-being of the patient, the planning and implementation of nursing care is essential to prevent this complication during the insertion and while the PVC is in situ in the patient.

Several studies have evaluated the risk factors for complications associated with PVC, especially phlebitis, ${ }^{2-3,5,8-9}$ with the aim of basing nursing practices and the implementation of patient care to prevent complications. ${ }^{10-12}$ The evidence highlighted in these studies is summarized in guidelines, which direct safe care associated with venous catheters. ${ }^{13-14}$

However, the literature highlights that nurses' knowledge regarding risk factors and PVC care in relation to complication prevention is sometimes insufficient and is not always applied to clinical practice, failing to meet the scientific evidence. ${ }^{15-16}$

Factors which motivated the present study: 1) phlebitis is one of the most common types of complications with high incidences and puts the safety and well-being of the patient at risk; 2) research is a tool that produces knowledge and can be used to substantiate nursing practices; and 3) the results of studies allow an analysis of current practices, planning and implementation of interventions, with a view to improving nursing care, especially in the area of peripheral venous catheter.

The following objectives were established: to understand the nursing practices related to peripheral venous catheter and to identify deviations from those established in the scientific evidence regarding the prevention of phlebitis.

\section{METHOD}

A qualitative study, using participant observation and individual interview with nurses from a medical clinic service in Portugal. Data collection was performed by the main researcher between June 2009 and February 2010. The choice of service was intentional due to most hospitalized patients using PVC and the nursing team expressing an interest in knowing the results of their practices and therefore being able to examine and improve them.

The inclusion criteria for the participant observation were: to be a nurse and to provide care to patients using PVC for at least three months in the selected scenario. Professionals on medical leave for a period exceeding 15 days were excluded from the study. All 26 nurses who worked in the service accepted to participate in the study and there was no exclusions or refusals. The participant observation technique was performed during the care provided by the nurses to patients with PVCs in situ, in the morning and afternoon shifts, with a greater presence in the morning. It should be mentioned that the research project was previously presented to the team and, considering the possibility that the presence of the researcher could influence the nurses' attitudes during the observation, it was chosen to perform the observations on different days and times and in at least five care activities, totaling 80 hours of observation. In addition, the research objectives and their possible contributions were presented to the nurses and a dialogue was established with the nurses during the observation. A minimum participation of the researcher in the activities was also sought, such as getting material, taking a tray, raising the head of the bed and clarifying doubts of the nurses when they asked for it, and involving the nurses in all stages of the research, aiming for a collective construction and the improvement of nursing practices. Such an approach mischaracterized the study as an evaluation 
process and provided an approximation with the nurses and the establishment of confidence, reducing the risk of influencing the results.

In order to support the observation, a data collection instrument was developed, which was based on guidelines on the subject under study. ${ }^{13-14}$ The observation began in the medication preparation room during the preparation of materials destined for peripheral venous puncture and/or medication and ended when the nurse returned to this room at the end of the procedure or in the patient's room when the nurse started another activity not related to the PVC.

The interview technique was performed at the end of the participant observation period. The following criteria were used to select the nurses participants for the individual interview: the nurse manager of the service, nurse-specialist who replaced the head of the care unit and collaborated in the management of the service, the nurse responsible for the educational actions in the service, the nurse who liaised with the Infection Control Commission, and the nurses who provided direct care to the patients (five nurses who presented practices that were more consonant with the guidelines, and another six according to the inverse ratio, according to the previous observation). There were no refusals, adding up to 15 interviews.

The interviews were conducted by the main researcher, using a script with three guiding questions that addressed the factors contributing to the occurrence of phlebitis in patients with PVCs, possible deviations and influences in nursing practices. Audio interviews were recorded (mean duration of 47 minutes) and transcribed in full.

The field notes from the participant observation and testimonials obtained in the interviews were transcribed in the Word for Windows program and exported to NVivo-Pro ${ }^{\circledR}$, version 10 for analysis. In order to preserve anonymity, the nurses were identified using uppercase letters, which were randomly assigned.

Content analysis was used following the phases of pre-analysis, material exploration and elaboration of thematic categories. ${ }^{17}$

\section{RESULTS}

The nurses participating in the study were predominantly female $(72 \%)$, with a mean age of 33.7 years $(24-54, \pm 7.1)$.

Three thematic categories emerged from the analysis of the field notes of the participant observation and the transcription of the interviews: Patients, Nursing Actions and Organization of care. Given the relevance of the findings, this study will present the category of nursing actions in detail (Table 1).

Table 1 - Category and subcategories resulting from the content analysis of the field notes from participant observation and interviews

\begin{tabular}{|c|c|}
\hline Category & Subcategories \\
\hline \multirow[t]{6}{*}{ Nursing actions } & Select anatomical site for venous puncture \\
\hline & Select catheter caliber \\
\hline & $\begin{array}{l}\text { Perform hand hygiene and disinfection of } \\
\text { materials }\end{array}$ \\
\hline & Evaluate presence of local changes \\
\hline & Maintain and secure the catheter \\
\hline & Involve the patient \\
\hline
\end{tabular}


In the subcategory Select anatomical site for venous puncture, it was verified that the nurses used different anatomical sites to cannulate the PVC. The majority used the upper limbs, namely the back of the hand and front and back of the forearm. However, the lower limbs were also used. One of the patients was cannulated in the leg, near the tibiotarsal joint (Observation).

The nurses recognized the risk of venous puncture on the lower limbs. However, the process arose in response to poor vein access in the upper limbs venous network, the absence of a Central Venous Catheter (CVC) as an alternative to PVC, and the imperative need for patients to have venous access. Thus, nurses sometimes sought to administer the prescribed drugs via the insertion of PVC in the lower limb. A few days ago, I asked myself if this makes sense! I was puncturing for the tenth time ... (Observation); In the case of this patient, she should not be punctured in the lower limbs because she is diabetic. But are you going to put a central catheter? (Nurse D).

In the subcategory Select catheter gauge, it can be verified that the selection of the PVC was considered by the nurses as being essential for the prevention of phlebitis, as this is considered one of the most common complications, according to the nurses' reports. However, most nurses selected the highest PVC caliber whenever the lumen of the vein allowed. In my opinion, the main complications in patients with PVCs is phlebitis (Nurse F). Sometimes, if you [maybe], cannulate with a 20 gauge catheter, when a 18 gauge could be used (Nurse Y). Only when it is not possible to use a pink catheter [20G], we use the blue one [22G] (Observation).

The subcategory Performing hand hygiene and disinfection of materials showed that the lack of washbasins in the patients' rooms influenced the performance of hand hygiene during the care of patients with PVCs. The only lavatory available in the room was in the medication preparation room and far away. There is a lack of washbasins in the rooms [...]. I know we have disinfectants, but hand wash basins have always been lacking and continue to do (Nurse T).

The nurses used elastic tourniquets or latex gloves before venous puncture. Sometimes the tourniquets stayed in the pocket of the nurses' uniforms and were used between patients without prior disinfection. Apply a rubber glove above the bend of the left arm (Observation); Removes elastic tourniquet from the pocket to initiate the cannulation without disinfection. (Observation).

Disinfection of needleless connector hubs that allow access to the PVC was sometimes not performed prior to the administration of venous therapy by the urses. However, they recognized the importance of this action for the prevention of phlebitis. I do not always disinfect the hubs, but I will start to take greater care with this procedure (Nurse T).

In the subcategory Evaluating presence of local changes, it was observed that the presence of pain at the PVC insertion site was referenced by some nurses as a fundamental clinical sign for the detection of phlebitis. The nurses observed the patient's facial expression and used this to indicate pain, since many patients had impaired verbal communication. I see the reaction or the face of the patient, which is important, because many of them do not speak, but complain; [...]. I was able to detect phlebitis only by the patients' facial expression (Nurse D).

In addition to pain at the PVC insertion site, the identification of phlebitis was also based on other local changes, such as redness, edema and heat. That redness of the vein, [...] it usually is, by the heat also, the site gets hot [...] (Nurse N).

The assessment of the PVC insertion site usually occurred before and during the administration of intravenous therapy, during the performance of patient positioning, before and after hygiene care and if there were any complaints from the patient.

The subcategory Maintaining and securing the catheter showed that patients had at least one or two PVCs. Among the reasons cited for this practice were the amount of medication prescribed and the difficulty of inserting a new PVC in certain patients who had poor vein access. Thus, the PVCs were maintained in situ until phlebitis or other complications occurred which justified their removal. 
The catheters stay ... because they are always getting blocked, the accesses are difficult and we always have the habit, if improperly, of keeping them (Nurse S).

In the subcategory Maintaining and securing the catheter it was observed that the PVC dressings were not identified with date, time and professional responsible for the insertion. However, nurses reported that duration was short, given the patient characteristics. Regarding the duration the catheter was to remain. They said that they did not know, but that the catheters in the service do not stay in situ for long periods (Observation).

The adhesive dressing that secured the PVC on the patient's skin was often removed after performing patient hygiene care, as they become wet during this care, although the primary dressing was kept near the insertion site. Failure to remove the primary dressing made it impossible to perform skin antisepsis and assess the insertion site for signs and symptoms of phlebitis. After performing patient hygiene care, he removed the white dressings that secured the catheter which were wet, without removing the last adhesive tape placed around the IV device cannula (Observation).

PVCs were often secured with non-sterile dressings. This was cut into strips before performing the venipuncture and stuck on the nurse's uniform, on the tray or on the bedside table. Take the roll of dressings you had on the tray and cut several strips. Then stick the dressing strips on the front of the uniform (Observation); He cut and stuck the white dressings on the edge of the table next to the patient (Observation).

The nurses considered it important to replace the dressing that secured the PVC daily, in order to observe the insertion site and detect phlebitis or any other complication. However, in many situations, the replacement of these dressings resulted in the accidental removal of the PVC and the need to insert a new catheter. When changing, dressings [...] I often have to take them off and I have to puncture again or because they bend or even because they fall out (Nurse D).

The transparent sterile dressing was available in the care unit, however, the nurses did not use it frequently. The use of the non-sterilized dressing was based on the absence of the transparent dressing in the service and this was not appropriate for many patients (elderly, confused and perspiring), since it was easily removed, leading to PVC removal. We often do not have adhesive dressings for catheters (Nurse Y). They come off more when the patient perspires, [...] (Nurse F).

To prevent the clear dressing from falling off, nurses used small, non-sterile adhesive tapes at the junction between the PVC and the insertion port, arguing that the catheters would be safer. The transparent sterile dressing available in the care unit were too small for adult patients and thus easily fell off. The film dressing [bandages] we do not use them, because they all fall off, they are pediatric size (Nurse W).

The nurses considered that the use of the non-sterile, brown-colored dressing to secure the PVC as a favorable factor for the occurrence of complications and the transparent sterile dressing as a protection factor, since it enabled them to observe the insertion site, in addition to being aseptic. Regarding the advantages of the dressing, I realize that it is important to observe the insertion site (Nurse S). Ever since I started working here, I think that most of the infections that I find in the catheter sites are related to the brown dressings (Nurse $\mathrm{O}$ ).

The subcategory Involving the patient refers to actions related to the teaching and guidance given to the patient, before and during the PVC insertion in relation to its maintenance.

The explanation given to the patient about the PVC insertion technique was minimal or absent, regardless of the patient's state of consciousness, often being limited to the phrase "I am going to put the needle in". It was also unusual to inform the patient about PVC care or signs and symptoms indicative of phlebitis, except for pain during drug administration. Ask the patient to tell you if you feel pain in the venous catheter site (Observation). 


\section{DISCUSSION}

The PVC-related nursing practices represent a large part of the nurses' work and focus on the prevention or identification of complications, ${ }^{18}$ with phlebitis being the most common ${ }^{2,4-7}$ However, a misalignment was identified between some actions and scientific evidence. ${ }^{13-14}$

Hand hygiene practices were not performed by the nurses of the present study at all times, ${ }^{19}$ with this action being influenced by the absence of lavatories in the rooms. Other reasons for the non-adherence of hand hygiene are highlighted in the literature, such as lack of time due to work overload and lack of knowledge about clinical situations to carry out hygiene with soap and water or antiseptics. ${ }^{19-20}$ In order to provide care in relation to hand hygiene, it is necessary to supervise the adoption of these practices and invest in training, in addition to providing materials and adjusting the infrastructure which is sometimes old or outdated such as rooms without washbasins. ${ }^{20-21}$

The absence of disposable tourniquets or cleaning and disinfection of the tourniquets between contact with patients during peripheral venous puncture was a practice among nurses and was corroborated in another study. ${ }^{22}$ Decontamination of tourniquets during patient care in different patients is essential to prevent infections related to the presence of PVCs, since the vast majority of tourniquets are contaminated with pathogenic microorganisms and have microbial resistance, such as Staphylococcus spp. ${ }^{21}$ This fact reinforces the need to implement institutional protocols for the substitution or disinfection of the tourniquets as well as educational in-service actions which are directed at giving professionals instructions about the importance of implementing this care in the nursing practices in order to prevent health care associated infections.

In the present study, it was verified that the selection of the caliber and the anatomic site used to insert the PVC in some situations were not those recommended by the guidelines, ${ }^{13-14}$ since the nurses usually selected the largest PVC caliber and inserted in the lower limb. Guidelines ${ }^{13-14}$ recommend the use of the smaller PVC caliber in order to prevent phlebitis as it enables blood flow in adjacent tissues and reduces contact between the catheter and the internal layer of the vein, thereby reducing the risk of vascular trauma. Several investigations confirm this recommendation, given the evidence of association between the largest PVC and the increased risk of phlebitis, ${ }^{4,23}$ although other studies have not shown such association. ${ }^{1-2}$

Regarding the anatomical site, the nurses' decision making in relation to the selection of the location of the PVC insertion was influenced by the patient characteristics and the venous access. Despite the technical skills demonstrated by nurses in relation to peripheral venous puncture, the multiple venous punctures performed in the patient and the absence of a CVC as an alternative to PVC contributed to them selecting the lower limb. This practice was based on the attempt to make intravenous drug administration feasible and is supported in a study ${ }^{24}$ on PVCs inserted in lower limbs in the absence of phlebitis.

The poor peripheral venous access and the risks associated with PVC and CVC should not be the only criteria involved when selecting the cannulation site or the type of catheter. ${ }^{13,26-27}$ This selection should include a comprehensive assessment of the patient (irritative, vesicant, $\mathrm{pH} \leq 5 \mathrm{or} \geq 9$, osmolarity $\geq 500 \mathrm{mOsm} / \mathrm{L}$ and infusion), the characteristics of the prescribed drugs (irritants, vesicants, $\mathrm{pH} \leq 5$ or $\geq 9$, with dextrose greater than $10 \%$ ), and the risks and benefits to the patient according to each type of catheter. ${ }^{13,25-26}$

Although care to prevent phlebitis is related to the prevention of bloodstream infection and these are established in guidelines, ${ }^{13,26}$ the present study highlights another practice in misalignment with these guidelines, namely the absence or inadequate disinfection of PVC needleless connector hubs. According to a recent study, $40 \%$ of the PVC three-way taps or connectors present external and intraluminal contamination by microorganisms that present a microbial resistance profile. ${ }^{27}$ In view of 
the risk of phlebitis and bloodstream infections, adherence to good safety practices for patient safety is essential. Therefore, new technologies, such as passive disinfection associated with the connectors have been used, which has evidenced lower rates of infection associated with the catheters. ${ }^{10,28}$ The adoption of this practice should be associated with hand hygiene, asepsis at the insertion site and the selection of disposable or sterilized tourniquets and, transparent and semipermeable dressings. ${ }^{13,26}$

Constant observation of the insertion site for signs and symptoms of complications, such as phlebitis, should be frequently practised by the nurse. In order to assist this observation, and standardize and document the signs and symptoms of phlebitis, the use of nurse validated scales is recommended, such as the phlebitis scale of the Infusion Nurses Society and the Portuguese Phlebitis Scale. ${ }^{29}$ These scales may also support decision making regarding the removal of a grade 1 PVC, which is when the first signs and symptoms of phlebitis are evident, thus avoiding further progression.

The identification and early communication of signs and symptoms of phlebitis, especially pain, was the main action performed by nurses and allowed the patient to participate in their own care process. Involving the patient in the selection of the venous catheter as well as the location and conducting educational guidelines, for example, are essential for the patient in relation to their selfcare and to prevent phlebitis and other complications related to the insertion and permanence of an intravenous catheter. ${ }^{5,13}$

Orientation must be given to patients and their relatives about signs and symptoms of postinfusion phlebitis after PVC removal during hospital discharge, considering that the incidence of this type of phlebitis reaches values up to $11 \% .^{30-31}$ The signs may develop within 48 hours, requiring evaluation by the nurse in the patients' residence or in a primary health care unit, in order to identify and implement appropriate therapeutic interventions. ${ }^{30-31}$

Non-adherence to the use of the sterile dressing which protects the PVC insertion site was another deviation identified in nursing practice, which is contrary to the recommendations for the prevention of phlebitis and infections. ${ }^{13-14}$ The purpose of the dressing is to protect the PVC insertion site against dirt, moisture ${ }^{8,27}$ and contact with external microorganisms, in addition to minimizing the movement of the catheter within the vein and prevent displacement, thus reducing the risk of peripheral vascular trauma. .,11,32 $^{2}$

In the present study, the non-adhesion to the sterile, impermeable transparent dressing by the nurses made it difficult to evaluate the PVC insertion site for the presence of signs and symptoms of vascular trauma, mainly phlebitis and infiltration. In order to evaluate the insertion site, it is necessary to remove a brown colored tape. In addition, these adhesive tapes often became wet during patient hygiene and required replacement, which culminated in the risk of accidental PVC exteriorization during the removal of the adhesive tape. Such a practice can be considered unsafe because it puts the safety of the patient at risk. The need to perform a new puncture results in patients feeling pain and anxiety, the increase in material costs and in nursing care time. ${ }^{3}$ Thus, it is necessary to carry out a review of nursing practices in relation to the type of dressings for securing the PVC to the skin of the patient. The use of sterile, semipermeable transparent dressing, which allows the observation of the PVC insertion site, would be a viable option which could be standardized in that service, since it was part of the available materials in the institution. However, it required the creation of a protocol in order to standardize the size and fixation technique in adult patients. These actions should be aligned with the in-service education and the sensitization of the nurses to use this type of dressing to secure the PVC in a safe and effective manner.

The use of non-sterile adhesive tape was another deviation identified in the nursing practices in the present study. Several professionals used the roll of adhesive tape and the strips to attach the PVC to the patient's skin, which were cut prior to cannulation and fixed to non-sterile surfaces such as the tray and uniforms. Since patient care involves direct contact with the nurse, and his or her 
uniform is a potential reservoir of microorganisms, ${ }^{33-34}$ the attachment of adhesive tape to the uniform is an unsafe practice, contributing to increase the risk of PVC associated bloodstream infections. Despite the lack of strong evidence regarding the best dressing to protect, fix and stabilize PVCs to the patient's skin and avoid complications, ${ }^{35}$ the use of a sterile dressing is consensual| ${ }^{13-14,26}$

The lack of identification of PVC dressings (date, time and professional responsible for the insertion) and the nurses' argument stating that the length of time the CVP in situ was short due to the frequent substitutions of the PVCs, contributed to a lack of control regarding the length of time the PVCs were left in situ. Recent studies suggest that PVC replacement occurs when clinically indicated $^{5-6,9,36}$ and removed as early as possible when it is not used. ${ }^{5,13-14}$ The fact that nurses in the present study maintain more than one PVC in the patient without any apparent need, may increase the risk of phlebitis, as found in another study. ${ }^{37}$

The findings of this study indicate the need for investment in regular in-service training and continuous education activities, so that nurses may update and acquire nursing care skills in the prevention and control of phlebitis and other complications related to the PVC. The results also suggest the creation of institutional protocols for adequacy and standardization of nursing practices in line with scientific evidence, with a view to patient safety and well-being.

This study is limited as the findings related to a single service, which does not permit the generalization of the results as well as posing the risk of the researcher having an influence on the nurses' attitudes during the participant observation, despite the use of the interview as another source of evidence, with a view to providing complementarity of results. However, the results demonstrated the complexity of nursing practices and evidenced deviations, which are related to organizational issues, knowledge and the adherence of nurses to scientific evidence.

\section{CONCLUSION}

Nursing practices presented deviations from the scientific evidence regarding the prevention of phlebitis. The following deviations were identified: sanitation practices were not always performed at all times and were influenced by the absence of washbasins in the rooms; inadequate selection of the catheter caliber at the time of PVC insertion; selection of the lower limb for PVC insertion, motivated by the patient characteristics and the unavailability of accessible veins; absence of disposable tourniquets or the disinfection of tourniquets between patients; use of non-sterile adhesive tape; non-adherence to the sterile, impermeable transparent dressing used to protect the PVC insertion site; and absence of identification alongside the PVC insertion (date, time and professional responsible for insertion). Many of these deviations have been influenced by institutional aspects, by the patient characteristics and by the lack of knowledge that these actions compromise the patient safety.

The creation of protocols which standardize nursing practices as well as the implementation of educational activities and the sensitization of nurses regarding risk factors for phlebitis, which are essential to guarantee a safe, quality care to the patient are proposed.

Studies on the use of new health technologies, such as the continuous passive disinfection of needleless connector hubs, involving the use of a protective cover containing antiseptic solution for disinfection, with the aim of improving the practice of disinfection of the hubs and reduce the incidence of catheter-related infections are recommended. In addition, the use of a Peripherally Inserted Central Venous Catheter (PICC) as an alternative to PVC and CVC, for patients with poor peripheral vein access or who present contraindications for PVC insertion. 


\section{REFERENCES}

1. Uslusoy E, Mete S. Predisposing factors to phlebitis in patients with peripheral intravenous catheters: a descriptive study. J Am Acad Nurse Pract [Internet]. 2008 Apr [cited 2017 Apr 03]; 20(4):172-80. Available from: https://dx.doi.org/10.1111/j.1745-7599.2008.00305.x

2. Abolfotouh MA, Salam M, Bani-Mustafa A, White D, Balkhy HH. Prospective study of incidence and predictors of peripheral intravenous catheter-induced complications. Ther Clin Risk Manag [Internet]. 2014 Dec [cited 2017 May 15];10:993-1001. Available from: https://www.ncbi.nlm.nih. gov/pubmed/25525365

3. Pasalioglu KB, Kaya $\mathrm{H}$. Catheter indwell time and phlebitis development during peripheral intravenous catheter administration. Pak J Med Sci. [Internet]. 2014 Jul [cited Aug 10, 2017]; 30(4):725-30. Available from: https://www.ncbi.nlm.nih.gov/pubmed/25097505

4. Wallis MC, McGrail M, Webster J, Marsh N, Gowardman J, Playford EG, et al. Risk factors for peripheral intravenous catheter failure: a multivariate analysis of data from a randomized controlled trial [Internet]. Infect Control Hosp Epidemiol. 2014 Jan [cited 2017 Jul 25];35(1):63-8. Available from: https://dx.doi.org/10.1086/674398

5. Braga LM, Parreira PM, Oliveira ASS, Mónico LSM, Arreguy-Sena C, Henriques MA. Phlebitis and infiltration: vascular trauma associated with the peripheral venous catheter. Rev Latino-Am Enfermagem. [Internet]. 2018 May [cited 2018 Aug 12];26:e3002. Available from: http://www. scielo.br/pdf/rlae/v26/0104-1169-rlae-26-e3002.pdf

6. Van Donk P, Rickard CM, McGrail MR, Doolan G. Routine replacement versus clinical monitoring of peripheral intravenous catheters in a regional hospital in the home program: a randomized controlled trial. Infect Control Hosp Epidemiol. [Internet]. 2009 Sept [cited 2017 Apr 03];30(9):9157. Available from: https://dx.doi.org/10.1086/599776

7. Abdul-Hak CK, Barros AF. The incidence of phlebitis in a Medical Clinical Unit. Texto Contexto Enferm [Internet]. 2014 Sept [cited 2017 Dec 15]; 23(3):633-8. Available from: https://dx.doi. org/10.1590/0104-07072014000900013

8. Avelar-Silva RN, Arreguy-Sena C. Peripheral vascular trauma in children: related factors by the logistic regression method. Rev Eletr Enf [Internet]. 2014 Jan/Mar [cited 2017 Jul 15]; 6(1):11724. Available from: https://dx.doi.org/10.5216/ree.v16i1.20145

9. Rickard CM, Webster J, Wallis MC, Marsh N, McGrail MR, French V, et al. Routine versus clinically indicated replacement of peripheral intravenous catheters: a randomised controlled equivalence trial. Lancet [Internet]. 2012 Sept [cited 2017 Dec 14];380(9847):1066-74. Available from: https:// dx.doi.org/10.1016/S0140-6736(12)61082-4

10. DeVries M, Mancos PS, Valentine MJ. Reducing bloodstream infection risk in central and peripheral intravenous lines: initial data on passive intravenous connector disinfection. J Vasc Acces [Internet]. 2014 Jun [cited 2018 Feb 15];19(2):87-93. Available from: https://dx.doi. org/10.1016/j.java.2014.02.002

11. Goossens GA, Hadaway L. Key strategies for improving outcomes of patients with peripheral venous catheters: report of an international panel discussion. J Vasc Acces [Internet]. 2014 Sept [cited 2017 Apr 03]; 19(3):135-7. Available from: https://dx.doi.org/10.1016/j.java.2014.05.001

12. Freixas N, Bella F, Limón E, Pujol M, Almirante B, Gudiol F. Impact of a multimodal intervention to reduce bloodstream infections related to vascular catheters in non-ICU wards: a multicentre study. Clin Microbiol Infect [Internet]. 2013 Sept [cited 2018 Mar 05];19(9):838-44. Available from: https://www.ncbi.nlm.nih.gov/pubmed/23130638

13. Gorski L, Hadaway L, Hagle ME, McGoldrick M, Orr M, Doellman D. Infusion therapy standards of practice. J Infus Nurs [Internet]. $2016 \mathrm{Jan} / \mathrm{Feb}$ [cited, 2017 Aug 02];39(1S):S1-160. Available from: http://source.yiboshi.com/20170417/1492425631944540325.pdf 
14. O'Grady NP, Alexander M, Burns LA, Dellinger EP, Garland J, Heard SO, et al. Guidelines for the prevention of intravascular catheter-related infections. Am J Infect Control [Internet]. 2011 May [cited 2017 Dec 15];39(4 Suppl 1):S1-34. Available from: https://www.ncbi.nlm.nih.gov/ pubmed/21511081

15. Cicolini G, Simonetti V, Comparcini D, Labeau S, Stijn B, Pelusi G, et al. Nurses' knowledge of evidence-based guidelines on the prevention of peripheral venous catheter-related infections: a multicentre survey. J Clin Nurs [Internet]. 2014 Sept [cited 2017 Aug 02];23(17-18):2578-88. Available from: https://www.ncbi.nlm.nih.gov/pubmed/24354398

16. Milutinović $D, \operatorname{Simin} D$, Zec $D$. Risk factor for phlebitis: a questionnaire study of nurses' perception. Rev Latino-Am Enfermagem [Internet]. 2015 Aug [cited 2018 Aug 12];23(4):677-84. Available from: http://www.scielo.br/scielo.php?script=sci_arttext\&pid=S0104-11692015000400677\&lng=en

17. Gondim SMG, Bendassolli PF. The use of the qualitative content analysis in Psychology: a critical review. Psicol Estud [Internet]. 2014 Apr/Jun [cited 2017 Jul 25];19(2):191-9. Available from: http://dx.doi.org/10.1590/1413-737220530002

18. Braga LM, Parreira PMSD, Arreguy-Sena C, Carlos DM, Mónico LSM, Henriques MAP. Incidence rate and the use of flushing in the prevention of obstructions of the peripheral venous catheter. Texto Contexto Enferm [Internet]. 2018 [cited 2019 Apr 16];27(4):e2810017. Available form: https://dx.doi.org/10.1590/0104-07072018002810017

19. Arntz PR, Hopman J, Nillesen M, Yalcin E, Bleeker-Rovers CP, Voss A, et al. Effectiveness of a multimodal hand hygiene improvement strategy in the emergency department. Am J Infect Control [Internet]. 2016 Nov [cited 2017 Dec 15];33(11):1203-7. Available from: https://www.ncbi. nlm.nih.gov/pubmed/27160981

20. Kampf G, Löffler H. Hand disinfection in hospitals - benefits and risks. J Dtsch Dermatol Ges [Internet]. 2010 Dec [cited 2017 Apr 03];8(12):978-83. Available from: https://www.ncbi.nIm.nih. gov/pubmed/20812991

21. Shobowale EO, Adegunle B, Onyedibe K. An assessment of hand hygiene practices of healthcare workers of a semi-urban teaching hospital using the five moments of hand hygiene. Niger Med J [Internet]. 2016 Jun [cited 2018 Feb 10];57(3):150-4. Available from: http://www.nigeriamedj. com/text.asp?2016/57/3/150/184058

22. Batista KCO, Tipple AFV, Leão-Vasconcelos LSNO, Ribeiro EL, Prado MA. Contamination of tourniquets for peripheral intravenous puncture. Acta Paul Enferm [Internet]. 2015 Sept/Oct [cited 2017 Dec 15]; 28(5):426-32. Available from: http://dx.doi.org/10.1590/1982-0194201500072

23. Cicolini G, Bonghi AP, Di Labio L, Di Mascio R. Position of peripheral venous cannulae and the incidence of thrombophlebitis: an observational study. J Adv Nurs [Internet]. 2009 Apr [cited 2017 Aug 02];65(6):1268-73. Available from: https://www.ncbi.nlm.nih.gov/pubmed/19374679

24. Benaya A, Schwartz Y, Kory R, Yinnon AM, Ben-Chetrit E. Relative incidence of phlebitis associated with peripheral intravenous catheters in the lower versus upper extremities. Eur J Clin Microbiol Infect Dis [Internet]. 2015 May [cited 2018 Feb 02];34(5):913-6. Available from: https://doi. org/10.1007/s10096-014-2304-7

25. Chopra V, Flanders SA, Saint S, Woller SC, O'Grady NP, Safdar N, et al. The Michigan Appropriateness Guide for Intravenous Catheters (MAGIC): results from a multispecialty panel using the RAND/UCLA appropriateness method. Ann Intern Med [Internet]. 2015 Sept [cited 2017 Jul 23];163(6 Suppl):S1-40. Available from: https://www.ncbi.nlm.nih.gov/pubmed/26369828

26. Loveday HP, Wilson JA, Pratt RJ, Golsorkhi M, Tingle A, Bak A, et al. epic3: national evidencebased guidelines for preventing healthcare-associated infections in NHS hospitals in England. $J$ Hosp Infect [Internet]. 2014 Jan [cited 2017 May 12];86(Suppl 1):S1-70. Available from: https:// dx.doi.org/10.1016/S0195-6701(13)60012-2 
27. Rossini FP, Andrade D, Santos LCS, Ferreira AM, Tieppo C, Watanabe E. Microbiological testing of devices used in maintaining peripheral venous catheters. Rev Latino-Am Enfermagem [Internet]. 2017 May [cited 2018 Feb 02];25:e2887. Available from: https://dx.doi.org/10.1590/15188345.1528.2887

28. Wright MO, Tropp J, Schora DM, Dillon-Grant M, Peterson K, Boehm S, et al. Continuous passive disinfection of catheter hubs prevents contamination and bloodstream infection. Am J Infect Control [Internet]. 2013 Jan [cited 2018 Feb 03];41(1):33-8. Available from: https://dx.doi. org/10.1016/j.ajic.2012.05.030

29. Braga LM, Salgueiro-Oliveira AS, Henriques MAP, Rodrigues MA, Rodrigues CJV, Pereira SAG, et al. Translation and adaptation of the Phlebitis Scale for the Portuguese population. Rev Enf Ref [Internet]. 2016 Nov [cited 2017 Feb 29]; SérielV(11):101-9. Available from: https://dx.doi. org/10.12707/RIV16048

30. Urbanetto JS, Peixoto CG, May TA. Incidence of phlebitis associated with the use of peripheral IV catheter and following catheter removal. Rev Latino-Am Enfermagem [Internet]. 2016 Aug [cited 2017 Dec 15];24:e2746. Available from: https://dx.doi.org/10.1590/1518-8345.0604.2746

31. Webster J, McGrail M, Marsh N, Wallis MC, Ray-Barruel G, Rickard CM. Postinfusion phlebitis: incidence and risk factors. Nurs Res Pract [Internet]. 2015 May [cited 2017 Aug 16];2015:691934. Available from: http://dx.doi.org/10.1155/2015/691934

32. Fourie A. Peripheral intravenous catheter performance: investigating peripheral intravenous catheter dwell times. Prof Nurs Today [Internet]. 2015 [cited, 2017 Jul 15];19(3):7-11. Available from: http://www.pntonline.co.za/index.php/PNT/article/view/786

33. Abu Radwan M, Ahmad M. The microorganisms on nurses' and health care workers' uniforms in the intensive care units. Clin Nurs Res [Internet]. 2017 Jun [cited 2017 Apr 03];28(1):94-106. Available from: https://doi.org/10.1177/1054773817708934

34. Morgan DJ, Liang SY, Smith CL, Johnson JK, Harris AD, Furuno JP, et al. Frequent multidrugresistant Acinetobacter baumannii contamination of gloves, gowns, and hands of healthcare workers. Infect Control Hosp Epidemiol [Internet]. 2015 Jan [cited 2018 Feb 15];31(7):716-21. Available from: https://dx.doi.org/10.1086/653201

35. Marsh N, Webster J, Mihala G, Rickard CM. Devices and dressings to secure peripheral venous catheters to prevent complications. Cochrane Database Sys Rev [Internet]. 2015 Jun [cited 2017 Dec 18];(6):CD011070. Available from: https://www.ncbi.nlm.nih.gov/pubmed/26068958

36. Ullman A, Keogh S, Marsh N, Rickard C. Routine versus clinically indicated replacement of peripheral catheters. Br J Nurs [Internet]. 2015 Jan [cited 2017 Aug 05];24(2):S14. Available from: https://doi.org/10.12968/bjon.2015.24.Sup2.S14

37. Pérez-Granda MJ, Guembe MR, Rincón C, Muñoz P, Bouza E. A prevalence survey of intravascular catheter use in a general hospital. J Vasc Access [Internet]. 2014 Nov/Dec [cited 2018 Feb 12]; 15(6):524-8. https://dx.doi.org/10.5301/jva.5000272 


\section{NOTES}

\section{ORIGIN OF THE ARTICLE}

Intervention in the practice of nurses in the prevention of phlebitis in people with peripheral venous catheters: an action research study presented at the Universidade de Lisboa and the Escola Superior de Enfermagem de Lisboa, in 2014.

\section{AUTHOR CONTRIBUTION}

Study design: Salgueiro-Oliveira AS, Basto ML, Parreira PMSD.

Data collect: Salgueiro-Oliveira AS.

Data analysis and interpretation: Salgueiro-Oliveira AS, Basto ML, Parreira PMSD.

Discussion of the results: Salgueiro-Oliveira AS, Basto ML, Parreira PMSD, Braga LM, Arreguy-Sena C, Melo MN.

Writing and/or critical review of content: Salgueiro-Oliveira AS, Basto ML, Parreira PMSD, Braga LM, Arreguy-Sena C, Melo MN

Review and final approval of the final version: Salgueiro-Oliveira AS, Basto ML, Parreira PMSD, Braga LM, Arreguy-Sena C, Melo MN

\section{FUNDING}

Program to support the advanced training of teachers of the Polytechnic Higher Education (PROTEC) of the Foundation for Science and Technology and the Nursing School of Coimbra.

\section{RESEARCH ETHICS COMMITTEE APPROVAL}

Approved by the Research Ethics Committee of the Board of Directors of the Hospital and the Ethics Committee, respectively (Ref 5 / CAPTA dated 06/03/2009, Opinion P156-04 / 2013).

\section{CONFLICT OF INTERESTS}

There is no conflict of interest.

\section{HISTORY}

Received: April 03, 2018.

Approved: November 06, 2018.

\section{CORRESPONDING AUTHOR}

Luciene Muniz Braga

luciene.muniz@ufv.br 